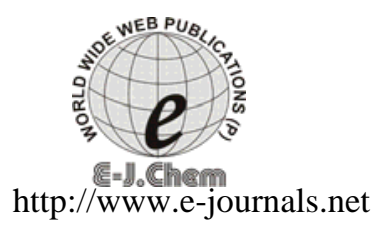

ISSN: 0973-4945; CODEN ECJHAO

E-Journal of Chemistry

2011, 8(S1), S195-S202

\title{
DFT and TD-DFT Study of Structure and Properties of Semiconductive Hybrid Networks Formed by Bismuth Halides and Different Polycyclic Aromatic Ligands
}

\author{
Y. BELHOCINE and M. BENCHARIF* \\ Rennes Chemistry Department (UMR CNRS 6226) \\ University of Rennes 1, Général Leclerc Avenue. \\ Rennes Cedex, 35042, France \\ Faculty of Sciences, Department of Chemistry \\ Mentouri University, Constantine, Algeria \\ jugurtha1977@yahoo.fr
}

Received 4 April 2011; Accepted 7 June 2011

\begin{abstract}
The structure and spectroscopic properties of polycyclic aromatic ligands of 2,3,6,7,10,11-hexakis (alkylthio) triphenylene (alkyl: methyl, ethyl, and isopropyl; corresponding to the abbreviations of the molecules: HMTT, HETT and HiPTT) were studied using density functional theory (DFT) and time dependent density functional theory (TD-DFT) methods with triple-zeta valence polarization (TZVP) basis set. It was shown that the type of functional theory used, Becke-Perdew (BP) and Leeuwen-Baerends (LB94) implemented in Amsterdam Density functional (ADF) program package, does not have essential influence on the geometry of studied compounds in both ground and excited states. However, significant differences were obtained for the band gap values with relativistic effects of the zero order regular approximation scalar corrections (ZORA) and LB94 functional seems to reproduce better the experimental optical band gap of these systems.
\end{abstract}

Keywords: Semiconductive hybrid networks, Electronic structure, DFT, Band gap

\section{Introduction}

Molecular conductors based on radical cations of tetrathiafulvalene (TTF) ${ }^{1}$ and its derivatives have been of major interest in the last decades ${ }^{2}$. The structures of molecular materials type donor-acceptor ${ }^{3}$, are built on stacks of organic cation with large transfer integrals between nearest neighbours to result in band formation, where partial filling due to removal of some 
electrons provide superconducting, metallic, spin density wave ${ }^{4}$, charge density wave and semiconducting states. The properties of these salts depend on structures of chemical modification of the organic cation or inorganic anion. The charge transport pathway in organic semiconductors ${ }^{5-7}$ is considered to be along the direction of maximum $\pi$ orbital overlap between the organic molecules subsystems. Some semi-empirical theoretical studies ${ }^{8}$ have been done on the dimensionality of these salts, which is generally imposed by the overlap mode developed in the organic subsystems. Among the numerous TTF ligand systems investigated in these last twenty years, the most extensively studied are those containing pyridine and bipyridine for the elaboration of metal complexes ${ }^{9}$. Like the first cobalt complexe containing TTF-pyridines based on the coordination of the $\mathrm{CoBr}_{2}$ fragment by tetradendate 4,5 bis(2-pyridyl-methylsulfanyl)-4',5'-ethylenedithio-TTF ${ }^{10,11}$. A variety of such class of compounds have been prepared by varying the included guest organic molecule, which leads to a new family of hybrid semiconductive coordination network ${ }^{12-15}$.

These extended structures based on organic-inorganic hybrids have been synthesized and reported by zhengtao $\mathrm{Xu}^{16}$. They are based on the coordination between bismuth trichloride and tribromide $\left(\mathrm{BiX}_{3}, \mathrm{X}=\mathrm{Cl}, \mathrm{Br}\right)$ and the different polycyclic aromatic ligands within multiple chelating thioether groups, that leads to the corresponding abbreviations: HMTT, HETT and HiPTT (Scheme 1).

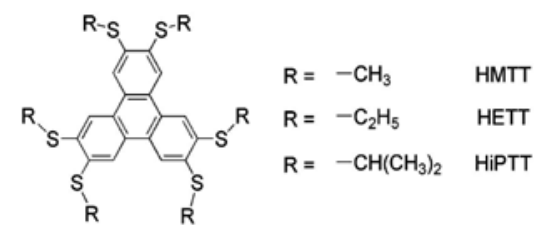

Scheme 1. Structure of the organic ligands with atom labelling

Do the solid-state electronic properties depend on nature of bond coordination of Bi-S and $\mathrm{Bi}-\mathrm{X}$ of such systems. What is the correlation between band gap and dimensionality ${ }^{17}$. A large number of density functional theory (DFT) studies have treated excited state properties based on the time-dependent (TD) method. Most of these studies employ the geometric structure of the electronic ground state ${ }^{18,19}$. DFT and TD-DFT methods are the most widely used tool for theoretically evaluating excited state energies and simulating the UV-vis spectra of organic and hybrids compounds in molecular and solid state level ${ }^{20}$. In this paper we present results of our studies of structure of polycyclic aromatic ligands of 2,3,6,7,10,11-hexakis (alkylthio) triphenylene in the molecular level with ADF.

\section{Experimental}

The problem of large organic materials is the inefficient predicting of the band gap. The $\pi-\pi$ interactions are one of the important noncovalent intermolecular forces especially when they involve aromatic rings, these weak bonds are problematic for DFT calculations and commonly used exchange-correlation functionals do not include effects such as dispersion interactions. The studied compounds are large systems and the electron correlation methods such as MP2 and $\operatorname{CCSD(T)~generally~treat~such~interactions~accurately,~but~these~}$ computations are difficult due to their high computational cost. DFT based methods, provide reasonable approximations with better computational efficiency. DFT method ${ }^{21}$ for ground state and TD-DFT ${ }^{22-24}$ for excited states calculations have been carried out with the Amsterdam Density Functional (ADF) program package ${ }^{25,26}$. Several pure and hybrid functionals were used but globally pure functionals (BP and LB94) gave better results. 
We also used pure meta-GGA functional M06-L for noncovalent interactions. The electronic configurations of all atoms were described by a valence-triple-polarized Slater-type orbitals (TVZP-STO) basis set ${ }^{27}$. For systems containing Bismuth atoms, the scalar relativistic effects of zero order regular approximation (ZORA) ${ }^{28,29}$ are considered. The core electrons were kept frozen. The geometries of studied compounds based on experimental X-ray were optimized in solid state and calculated at LB94 and BP level theory without any symmetry constraints.

\section{Results and Discussion}

\section{Structural studies}

These compounds ${ }^{16}$ (Figure 1) feature different dimensionalities ${ }^{30,31}$ architectures framework from $0 \mathrm{D}$ to 2D. The experimental measurements of the electronic band gap of all compounds vary between $1.64 \mathrm{eV}$ for the 2D network of $3-\mathrm{HMTT} \cdot 2 \mathrm{BiBr}_{3}$ to $2.98 \mathrm{eV}$ for the isolated (0D) HMTT, suggesting that $\mathrm{Bi}-\mathrm{S}$ and $\mathrm{Bi}-\mathrm{X}$ bonds improve the electronic interactions rather than $\pi$ - $\pi$ stacks interactions between organic molecules.
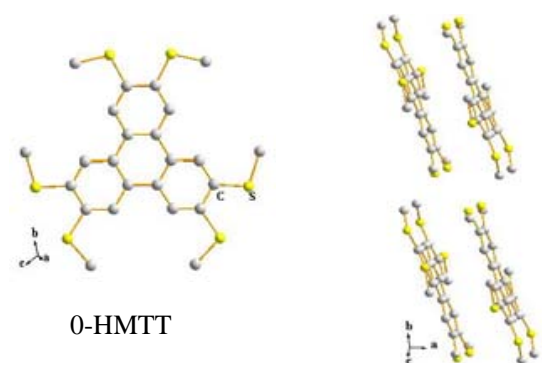

Illustration of adjacent stacks in HMTT
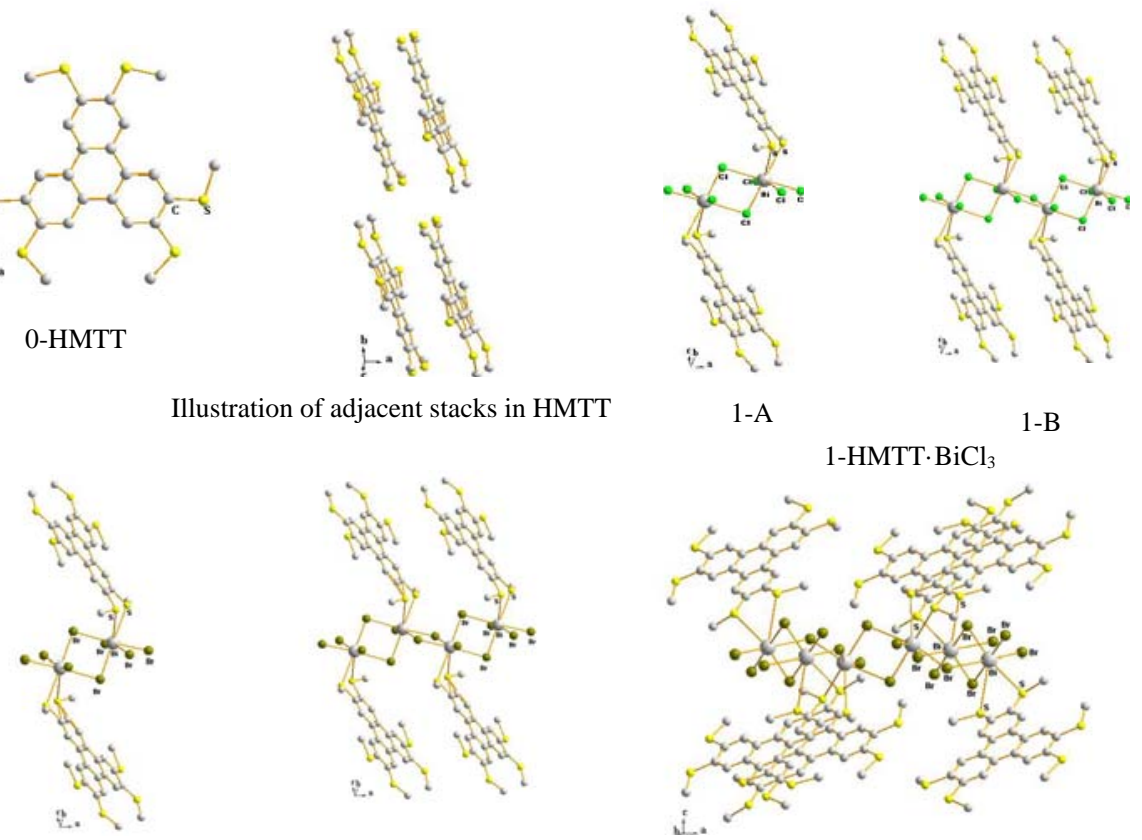

2-A

$$
\text { 2-B }
$$

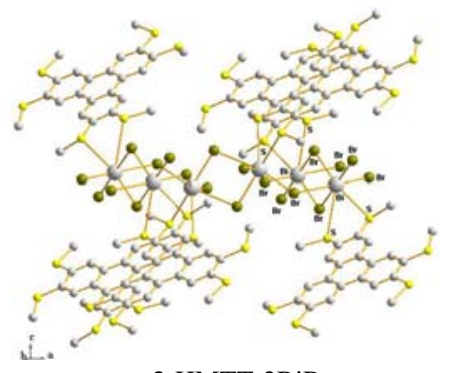

3-HMTT·2BiBr 3

2-HMTT·BiBr 3

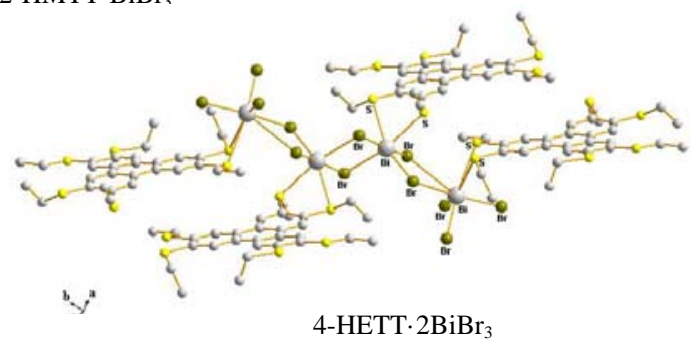

Figure 1. Molecular structure of compounds; 0-HMTT, 1-HMTT $\cdot \mathrm{BiCl}_{3}, 2-\mathrm{HMTT} \mathrm{BiBr}_{3}$, 3-HMTT·2 $\mathrm{BiBr}_{3}, 4-\mathrm{HETT} \cdot 2 \mathrm{BiBr}_{3}$. (Hydrogen atoms were omitted for clarity) 
We notice, in all structures, the intermolecular packing of columns of organic ligands which is dominated by $\pi-\pi$ stacking $^{32}$ of the large aromatic molecules. The calculated bond lengths from optimized structures, are listed in Table 1 and compared with the corresponding values from the X-ray data.

Table 1. Structural and electronic parameters of all described compounds

\begin{tabular}{|c|c|c|c|c|c|}
\hline Compounds & $\begin{array}{c}\text { Optical } \\
\text { band gap } \\
\text { [e.V] }\end{array}$ & $\begin{array}{c}\text { Bi-S } \\
\text { distances } \\
(\AA) \text { X-Ray } \\
\text { data }\end{array}$ & $\begin{array}{l}\text { Bi-X distances } \\
(\AA) X-R a y \text { data }\end{array}$ & $\begin{array}{c}\text { Bi-S } \\
\text { distances } \\
(\AA) \\
\text { Calculated }\end{array}$ & $\begin{array}{l}\text { Bi-X distances } \\
(\AA) \text { Calculated }\end{array}$ \\
\hline 0-НMTT & 2.98 & None & None & None & None \\
\hline 1-HMTT· $\mathrm{BiCl}_{3}$ & 1.82 & $3.01,3.25$ & $\begin{array}{l}\text { 2.47,2.58,2.67, } \\
2.923 .27\end{array}$ & $2.98,3.13$ & $\begin{array}{l}\text { 2.55,2.69,2.77, } \\
2.793 .02\end{array}$ \\
\hline 2-HMTT· $\mathrm{BiBr}_{3}$ & 1.75 & $3.03,3.30$ & $\begin{array}{l}\text { 2.62, } 2.72 \text { 2.80, } \\
3.073 .48\end{array}$ & $2.93,3.17$ & $\begin{array}{l}2.68,2.82 \\
2.91,2.953 .35\end{array}$ \\
\hline 3- $\mathrm{HMTT} \cdot 2 \mathrm{BiBr}_{3}$ & 1.64 & $\begin{array}{l}3.10,3.12 \\
3.31,3.45\end{array}$ & $\begin{array}{l}2.62,2.642 .65 \text {, } \\
2.72 \text { 2.72, } 2.75 \\
3.263 .293 .30 \text {, } \\
3.40\end{array}$ & $\begin{array}{l}3.08,3.09 \\
3.23,3.39\end{array}$ & $\begin{array}{l}2.67,2.68 \\
2.73,2.77 \\
2.80,2.83 \\
3.13,3.18 \\
3.18,3.26\end{array}$ \\
\hline 4-HETT·2BiBr 3 & 1.97 & 2.91, 3.04 & $\begin{array}{l}\text { 2.67, } 2.68 \text { 2.85, } \\
3.11\end{array}$ & 2.86, 2.96 & $\begin{array}{l}2.73,2.73 \\
2.94,3.01\end{array}$ \\
\hline
\end{tabular}

\section{DFT calculations}

At non-relativistic level using $\mathrm{BP}^{33}$ and $\mathrm{LB}^{34}{ }^{34}$ functionals, we notice that BP functional gives good estimation of the gap, as mentioned in Table 2. The relativistic effects of the ZORA scalar corrections doesn't influence substantially the band gap values obtained, except for 3-HMTT•2BiBr . For the compounds 0-HMTT, 2- $\mathrm{HMTT} \bullet \mathrm{BiBr}_{3}$ and 4-HETT•2BiBr , the deviations from experimental values are $0.23 \mathrm{eV}, 0.18$ and 0.17 respectively. The use of LB94 functional at relativistic level, provide a better agreement with experimental values. LB94 functional satisfy the asymptotic conditions and improves the performance of computing long range behaviour.

Table 2. Band gap calculated energies at DFT molecular level

\begin{tabular}{|c|c|c|c|c|c|}
\hline \multirow[b]{2}{*}{ Compound } & \multirow[b]{2}{*}{$\begin{array}{l}\mathrm{Gap}_{\exp } \\
{[\mathrm{eV}]}\end{array}$} & \multicolumn{4}{|c|}{ Calculated gaps (ADF) [eV] } \\
\hline & & $\begin{array}{l}\text { GGA-BP }^{\mathrm{a}} \\
\text { X-ray data }\end{array}$ & $\begin{array}{l}\text { GGA-BP }^{\text {a }} \\
\text { calculated }\end{array}$ & $\begin{array}{l}\text { GGA-BP }^{b} \\
\text { calculated }\end{array}$ & $\begin{array}{c}\text { GGA-LB94 }^{b} \\
\text { calculated }\end{array}$ \\
\hline 0-НMTT & 2.98 & 2.77 & 2.75 & 2.75 & 2.53 \\
\hline $1-\mathrm{HMTT} \cdot \mathrm{BiCl}_{3}(1-\mathrm{A})$ & 1.82 & 2.10 & 1.87 & 1.83 & 1.70 \\
\hline $2-\mathrm{HMTT} \cdot \mathrm{BiBr}_{3}(2-\mathrm{A})$ & 1.75 & 2.13 & 1.98 & 1.93 & 1.87 \\
\hline $3-\mathrm{HMTT} \cdot 2 \mathrm{BiBr}_{3}$ & 1.64 & 2.09 & 1.82 & 1.76 & 1.66 \\
\hline $4-\mathrm{HMTT} \cdot 2 \mathrm{BiBr}_{3}$ & 1.97 & 2.19 & 2.04 & 2.14 & 2.05 \\
\hline
\end{tabular}

a: The energy gaps were calculated using the DFT theory and triple-zeta polarized (TZP) basis.

b: The energy gaps were calculated using the DFT theory and triple-zeta polarized (TZP) basis with the addition of relativistic scalar ZORA correction

We also carried out calculations on first compound (0-HMTT) using the M06- $\mathrm{L}^{35}$ functional, which yields good results, but $\mathrm{M}^{3} 6^{36}$ family of functionals is not well tested for large systems containing heavy elements. Therefore, the results obtained for other compounds are not reliable. 


\section{TD-DFT calculations}

Single point time dependent density functional theory ${ }^{37-39}$ calculations including ten lowest singlet-singlet transitions were performed by employing the GGA-BP functional at non relativistic level, in order to obtain the character of electronic transition and oscillator strength of 0 -HMTT, 1-HMTT $\bullet \mathrm{BiCl}_{3}$ (1-A). The results are listed in Table 3. Only the singlet-singlet transitions are mentioned, singlet-triplet transitions are not optically forbidden but they correspond to zero strength oscillator. We can notice that the calculated energies of $\mathrm{S}_{0}$ state which correspond to the lowest excitation energy occur at equivalent energies with those of DFT level. The highest occupied molecular orbital (HOMO) of the system involved in the transition is mainly localized on the organic part, while the lowest unoccupied molecular orbital (LUMO) is entirely confined by the $\mathrm{BiCl}_{3}$ entity as illustrated in the molecular orbital (MO) plots and displayed in Figure 2. Similar conclusions are obtained for compound 1-HMTT•BiBr 3 (1-A). Two major electronic transitions for the compound 0HMTT exhibiting a large oscillator strength and assigned to $\mathrm{S}_{0^{---}} \mathrm{S}_{4}$ and $\mathrm{S}_{0^{---}} \mathrm{S}_{5}$ correspond essentially to HOMO-LUMO+1, HOMO-1-LUMO, and HOMO-1-LUMO+2, HOMOLUMO and their energies are close to the experimental gap. These excitations are local type within 0 -HMTT. The visibility of the $\mathrm{S}_{0^{---}-\mathrm{S}_{1,2,3}}$ transitions seems highly improbable, since the oscillator strength is very weak. However, for $1-\mathrm{HMTT} \bullet \mathrm{BiCl}_{3}(1-\mathrm{A})$, the $\mathrm{S}_{0}---\mathrm{S}_{1}$ transition which correspond to HOMO-LUMO excitation, is pure charge transfer type.

Table 3. TDDFT calculation of excitation energies (E) and oscillator strengths (f) of the lowest excited singlet-singlet states

\begin{tabular}{cccccc}
\hline \multicolumn{3}{c}{ 0-HMTT ${ }^{\text {a }]}$} & \multicolumn{3}{c}{ 1-HMTT·BiCl ${ }_{3}(1-\mathrm{A})^{[\mathrm{a}]}$} \\
\hline TD-DFT state & $\mathrm{E}[\mathrm{ev}]$ & $\mathrm{f}$ & TD-DFT state & $\mathrm{E}[\mathrm{ev}]$ & $\mathrm{f}$ \\
\hline $\mathrm{S}_{0}$ & 2.80 & 0.000007 & $\mathrm{~S}_{0}$ & 1.88 & 0.00592 \\
$\mathrm{~S}_{1}$ & 2.87 & 0.000266 & $\mathrm{~S}_{1}$ & 2.03 & 0.09055 \\
$\mathrm{~S}_{2}$ & 2.90 & 0.002620 & $\mathrm{~S}_{2}$ & 2.24 & 0.02133 \\
$\mathrm{~S}_{3}$ & 2.97 & 0.001608 & $\mathrm{~S}_{3}$ & 2.38 & 0.02888 \\
$\mathrm{~S}_{4}$ & 3.19 & 0.286500 & $\mathrm{~S}_{4}$ & 2.46 & 0.00040 \\
$\mathrm{~S}_{5}$ & 3.21 & 0.294900 & $\mathrm{~S}_{5}$ & 2.52 & 0.00120 \\
$\mathrm{~S}_{6}$ & 345 & 0.076080 & $\mathrm{~S}_{6}$ & 2.56 & 0.09946 \\
$\mathrm{~S}_{7}$ & 3.47 & 0.031130 & $\mathrm{~S}_{7}$ & 2.62 & 0.01436 \\
$\mathrm{~S}_{8}$ & 3.48 & 0.007941 & $\mathrm{~S}_{8}$ & 2.64 & 0.01972 \\
$\mathrm{~S}_{9}$ & 3.49 & 0.120800 & $\mathrm{~S}_{9}$ & 2.65 & 0.02037 \\
\hline
\end{tabular}

a: The energy gaps were calculated using the DFT-BP functional at non relativistic level

The frontier orbitals ${ }^{40}$ of the studied compounds, calculated at the GGA-LB94 ${ }^{41,42} / \mathrm{TZP}$ and relativistic level of theory are shown in Figure 2. The HOMO's show contributions exclusively from the organic ligands in almost constant percentage and are generally of bonding character, while the LUMO's are most of antibonding character and essentially delocalized over the inorganic chain. It is interesting to notice that the frontier orbitals of compound 1-HMTT $\bullet \mathrm{BiCl}_{3}$ and $2-\mathrm{HMTT} \bullet \mathrm{BiBr}_{3}$ are quite the same, producing a similar band gap, 1.82 and 1.75 respectively and similar electronic transitions. The interactions between orbitals of $\mathrm{Bi}$ and $\mathrm{S}$ atoms are of antibonding character, they increase the band gap value whereas major interactions between $\mathrm{Bi}$ and $\mathrm{Br}$ atoms of bonding character are getting shorter and decrease the band gap. 


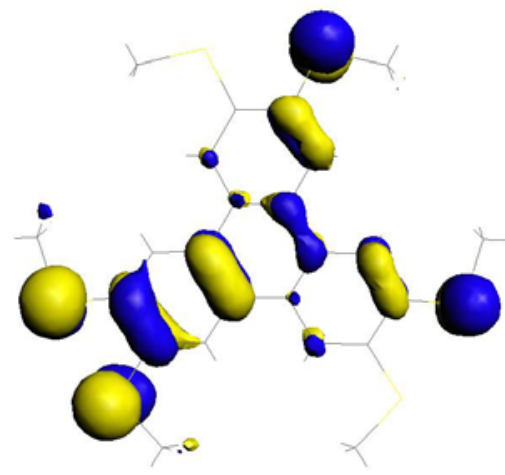

HOMO

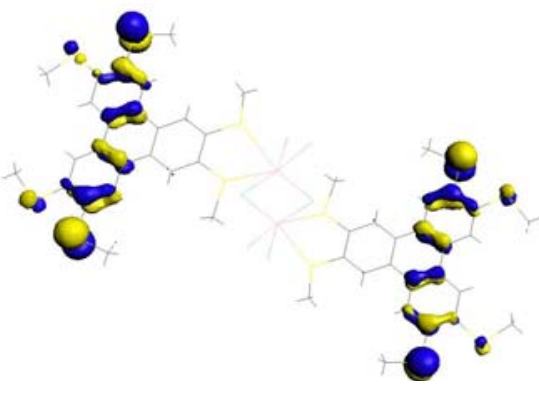

HOMO

$1-\mathrm{HMTT} \cdot \mathrm{BiCl}_{3}$

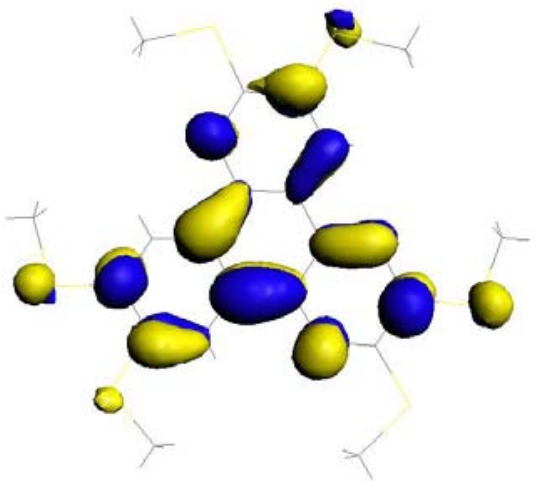

LUMO

0-HMTT

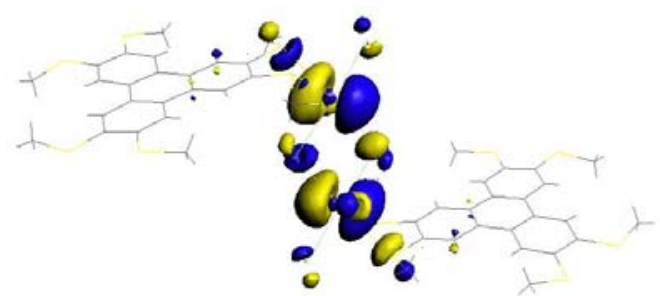

LUMO

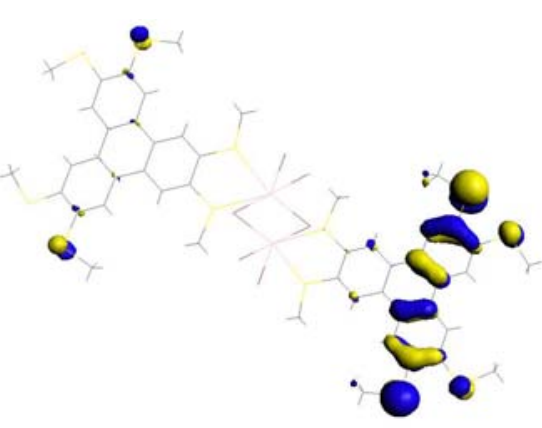

HOMO

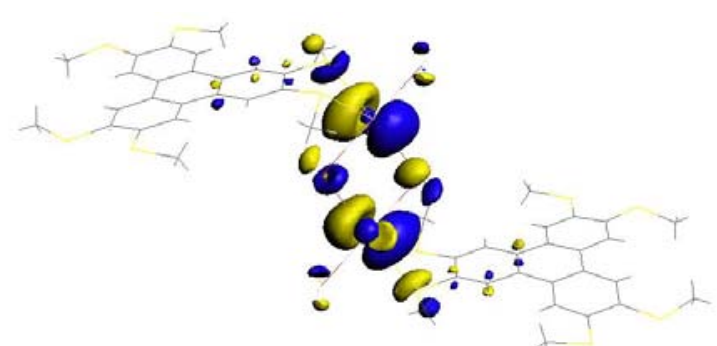

LUMO

Figure 2. Contour plots of the frontier molecular orbitals of compounds 0-HMTT, 1$\mathrm{HMTT} \cdot \mathrm{BiCl}_{3}$ and 2-HMTT$\cdot \mathrm{BiBr}_{3}$

\section{Conclusion}

In this paper, the structural and band gap of a semiconductive network hybrid compounds were computationally explored. Their vertical singlet-singlet electronic excitations were calculated and characterized by employing TD-DFT methods. We have assessed the efficiency of different methods and functionals for calculating the optical band gaps. It was found that theoretical calculations at molecular level were adequate to provide a reliable accuracy for estimation of the band gap, notably when using rationalized functionals such 
LB94 in the aim of reproducing the experimental values. The TD-DFT calculations point out that the most probable two transitions of HMTT belong to the local excitations, and the $\mathrm{S}_{0^{-}--\mathrm{S}_{1}}$ transitions for $1-\mathrm{HMTT} \bullet \mathrm{BiCl}_{3}$ and $2-\mathrm{HMTT} \bullet \mathrm{BiBr}_{3}$ belong to the charge transfert excitations. For the present structures, the LUMO, which consists essentially of Bi-X bonds of the inorganic networks, is the key issue in determining the band gap, and the variations of the frontier orbital energies resulting in reduced band gaps correlates well with the increase of dimensionality.

\section{Acknowledgment}

This work has been supported by the Ministry of Higher Education and Scientific research (MESRS-Algeria) trough the national exceptional program (PNE) grant, the authors wish to thank Dr. Jean-François Halet and Dr. Régis Gautier, Rennes 1 University, for their technical support and Programs facilities.

\section{References}

1. $\quad$ Ferraris J, Cowan D O, Walatka V and Perlstein J H, J Am Chem Soc., 1973, 95, 948-949.

2. Barisic S, Bejelis A, Cooper J R and Leontic B, Proceedings of the International Conference on quasi one-dimensional conductors; Eds., Springer-Verlag Berlin, 1978.

3. Horiuchi S, Hasegawa T and Tokura Y, J Phys Soc Jpn., 2006, 75, 051016.

4. $\quad$ Canadell E and Whangbo M H, Phys Rev B, 1991, 43(3), 1894-1902.

5. Brocks G and Tol A, J Phys Chem., 1996, 100, 1838-1846.

6. Leontie L and Danac R, Scripta Materialia., 2006, 54(2), 175-179.

7. Horowitz G, Adv Mater., 1990, 2, 287-292.

8. Ouahab L, Bencharif M, Mhanni A, Pelloquin D, Halet J F, Peña O, Padiou J, Grandjean D, Garrigou-lagrange C, Amiell J and Delhaes P, Chem Mater., 1992, 4, 666-674.

9. Lorcy D, Bellec N, Fourmigué M and Arvari N, Coord Chem Rev., 2009, 253, 1398-1438.

10. Liu S X, Dolder S, Franz P, Neels A, Stoeckli-Evans H and Decurtins S, Inorg Chem., 2003, 42(16), 4801-4803.

11. Liu S X, Ambrus C, Dolder S, Neels A and Decurtins S, Inorg Chem., 2006, 45(24), 9622-9624.

12. Xu Z, Coord Chem Rev., 2006, 250, 2745-2757.

13. Li K, Xu Z and Fettinger J C, Inorg Chem., 2004, 43, 8018-8022.

14. Li K, Xu Z, Xu H, Caroll P J and Fettinger J C, Inorg Chem., 2006, 45, 1032-1037.

15. Li K, Xu H, Xu Z, Zeller M and Hunter A D, Inorg Chem., 2005, 44, 8855- 8860.

16. Li K, Xu Z, Xu H and Ryan J M, Chem Mater., 2005, 17, 4426-4437.

17. Huang G, Sun Y Q, Xu Z, Zeller M and Hunter A D, Dalton Trans., 2009, 26, 5083-5093.

18. de Groot M and Wybren J B, Chem Phys Lett., 2007, 435(4-6), 224-229.

19. Snehalatha M, Ravikumar C, Sekar N, Jayakumar V S and Joe I H, J Raman Spectrosc., 2008, 39, 928-936.

20. Guzow K, Milewska M, Czaplewski C and Wiczk W, Spect Acta A Mol Biomol Spectrosc., 2010, 75, 773-781.

21. Parr R G and Yang W, Ann Rev Phys Chem., 1995, 46, 701-728.

22. Casida M E, Recent Advances in Density Functional Methods; Part I, Edited by Chong D P, World Scientific: Singapore, 1995, 155.

23. Bauernschmitt R and Ahlrichs R, Chem Phys Lett., 1996, 256(4-5), 454-464. 
24. Furche F, J Chem Phys., 2001, 114(14), 5982-5992.

25. te Velde G, Bickelhaupt F M, Van Gisbergen S J A, Fonseca Guerra C, Baerends E J, Snijders J G and Ziegler T, J Comp Chem., 2001, 22, 931-967.

26. Fonseca Guerra C, Snijders J G, te Velde G and Baerends E J, Theor Chem Acc.,1998, 99, 391-403.

27. Van Lenthe E and Baerends E J, J Comp Chem., 2003, 24, 1142-1156.

28. Van Lenthe E, Baerends E J and Snijders J G, J Chem Phys., 1993, 99, 4597- 4610.

29. Van Lenthe E, Baerends E J and Snijders J G, J Chem Phys., 1994, 101, 9783-9792.

30. Rosi N L, Eddaoudi M, Kim J, O’keeffe M, Yaghi O M, Angew Chem Int Ed., 2002, 41, 284-287.

31. Cai L Z, Guo G C, Fu M L, Wang M S, Chen W T and Huang J S, InorganicaChimica Acta, 2006, 359(14), 4483-4492.

32. Zheng S L, Zhang J P, Wong W T and Chen X M, J Am Chem Soc., 2003, 125, 6882-6883.

33. Becke A D, Phys Rev A, 1988, 38(6), 3098-3100.

34. Van Leeuwen R and Baerends E J, Phys Rev A ,1994, 49, 2421-2431.

35. Zhao Y and Truhlar D G, J Chem Phys., 2009, 130, 074103.

36. Zhao Y and Truhlar D G, Theor Chem Acc., 2008, 120, 215-241.

37. Hirata S, Lee T J and Head-Gordon M, J Chem Phys., 1999, 111, 8904-8912.

38. Hirata S and Head-Gordon M, Chem Phys Lett., 1999, 302, 375-382.

39. Hirata S, Head-Gordon M, Szczepanski J and Vala M, J Phys Chem A, 2003, 107, 4940-4951.

40. Weber-Bargioni A, Auwärter W, Klappenberger F, Reichert J, Lefrançois S, Strunskus T, Wöll C, Schiffrin A, Pennec Y and Barth, J V, Chem Phys Chem., 2008, 9, 89-94.

41. Hirata S and Head-Gordon M, Chem Phys Lett., 1999, 314, 291-299.

42. Imamura Y and Nakai H, Chem Phys Lett., 2006, 419(1-3), 297-303. 


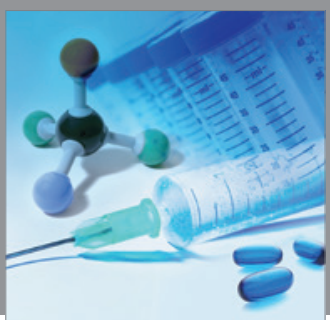

International Journal of

Medicinal Chemistry

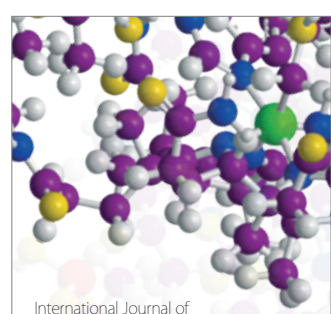

Carbohydrate Chemistry

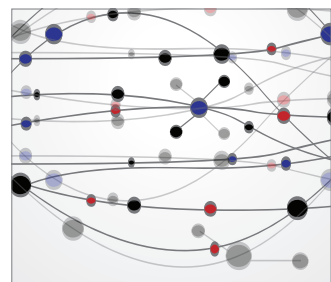

The Scientific World Journal
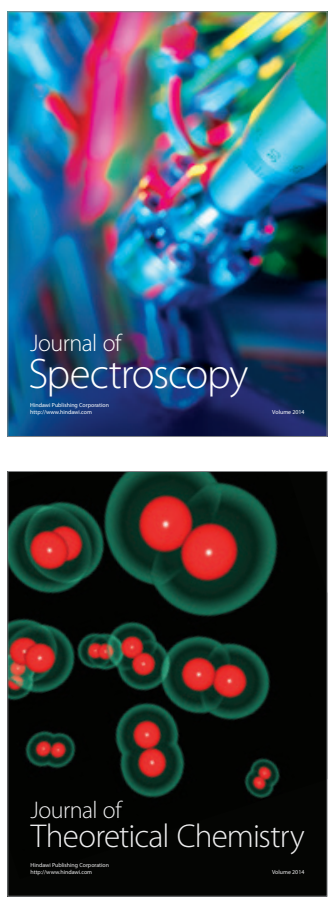
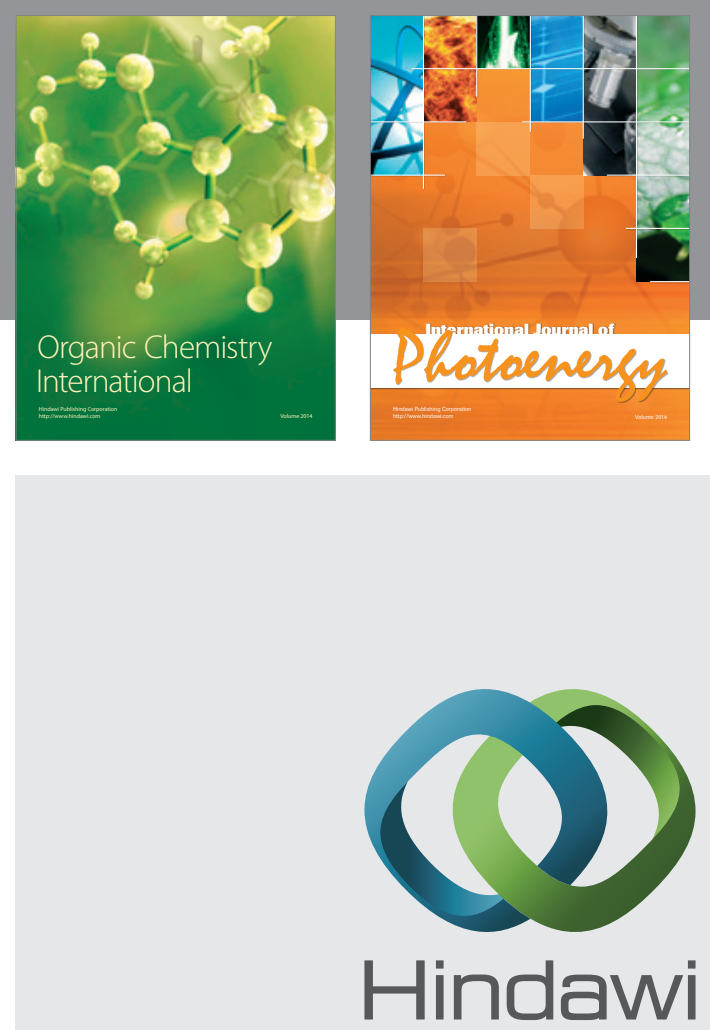

Submit your manuscripts at

http://www.hindawi.com
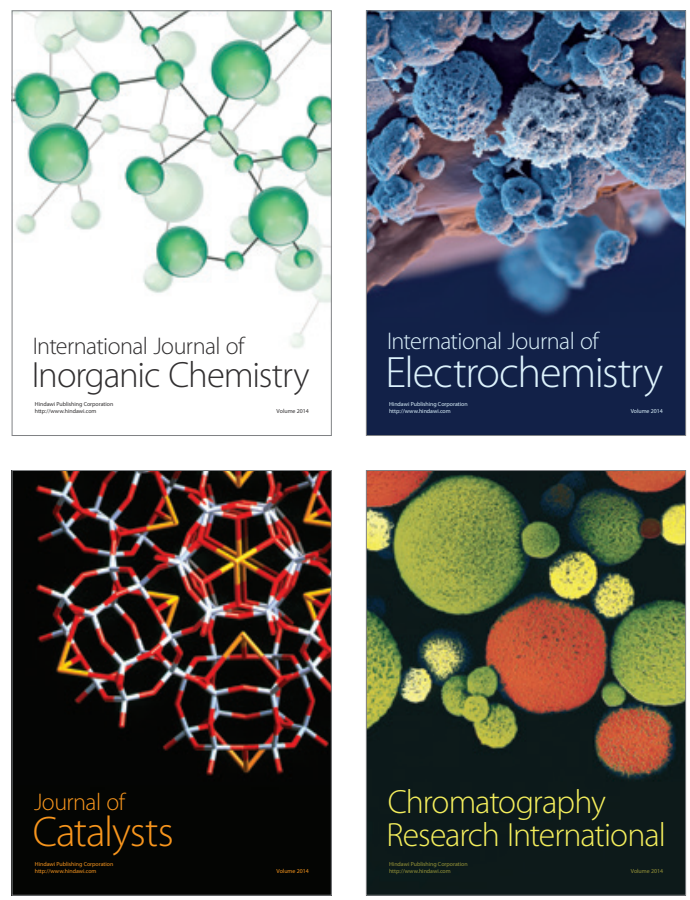
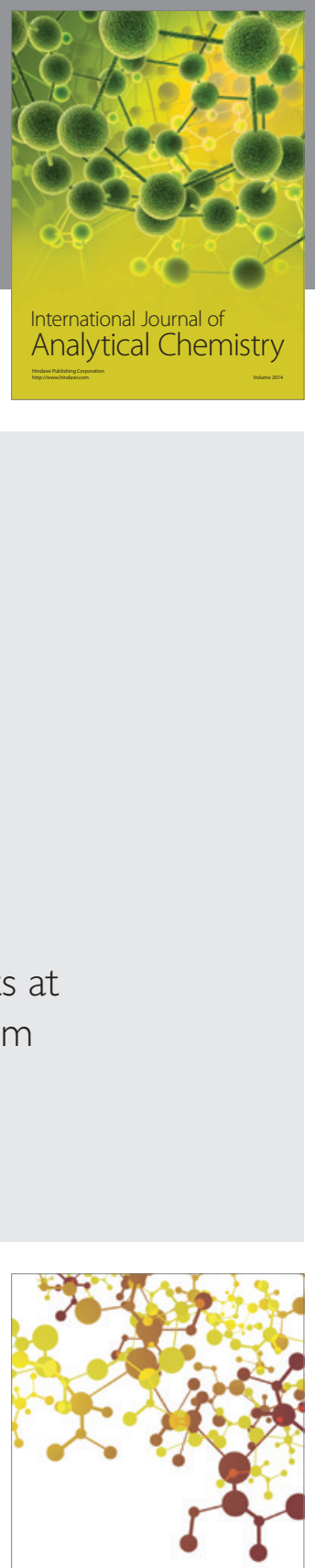

Journal of

Applied Chemistry
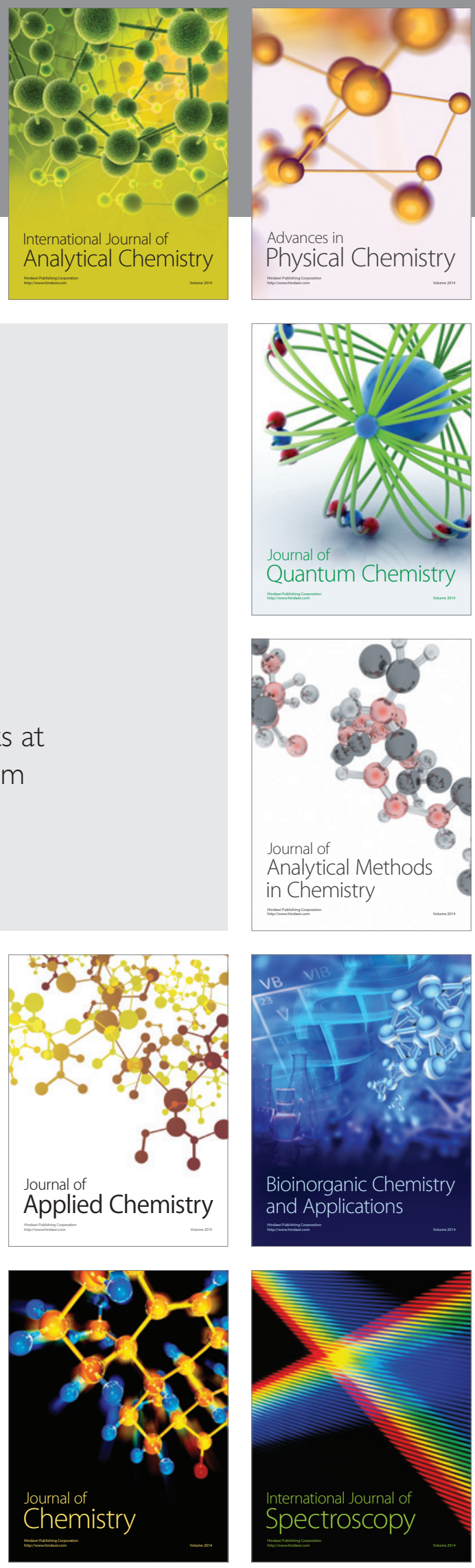